\title{
Tyrosine Phosphorylation
}

National Cancer Institute

\section{Source}

National Cancer Institute. Tyrosine Phosphorylation. NCI Thesaurus. Code C18497.

Tyrosine phosphorylation involves the introduction of a phosphoryl group into a

compound through the formation of an ester bond between a tyrosine residue in the compound and a phosphorus moiety. 